Scientia studia, São Paulo, v. 9, n. 1, p. 79-104, 2011

\title{
st \\ Intermitências da morte: redefinições do ser humano na difusão da morte cerebral como fato médico
}

Luciana Kind

\begin{abstract}
$\stackrel{\circ}{\because 3}$
RESUMO

Este artigo apresenta diferentes definições de morte cerebral, resgatando parte do processo de sua construção como fato médico. Desde o final dos anos 1960, quando foi publicada em importante veículo de divulgação científica da comunidade médica, o Journal of the American MedicalAssociation, a definição de morte cerebral suscitou adesões e contraposições. De modo a se afirmar em textos estatutários, a definição foi ganhando novos contornos, sendo consolidada como whole-brain death no alvorecer dos anos 1980. Compondo esse processo, outras definições vão sendo oferecidas como alternativas para a wholebrain death. As definições de brainstem death e a higher brain death ganham destaque nesse processo histórico de construções de argumentos. Para alcançar o status de "boa" definição, cada uma delas se apoiou em específicas delimitações de "ser humano". Nessas redefinições da morte que se desenrolam entre os anos 1960 e 1990, concepções de ser humano afirmavam-se pela localização no cérebro ou no organismo como um todo, ou pela presença da "pessoalidade", da "identidade pessoal" ou de "estabilidade moral".
\end{abstract}

Palavras-chave $\bullet$ Morte cerebral. Concepções de ser humano. Whole-brain death. Brainstem death. Higher brain death.

Os textos científicos parecem aborrecidos e sem vida, de um ponto de vista superficial. Se o leitor recompuser os desafios que esses textos enfrentam, eles passarão a ser tão emocionantes quanto um romance.

(Latour, 2000, p. 90)

"No dia seguinte, ninguém morreu". Esta frase enigmática inicia e finaliza o romance de Saramago, do qual se busca inspiração para o título deste artigo. No romance, a personagem principal é a morte. Dentro das fronteiras de um país imaginário, a morte se priva da tarefa de ceifar vidas. O drama vivido pelos habitantes do país se resolve com o simples cruzamento da "linha invisível" de suas fronteiras. Deslocados geograficamente, os moribundos mudam de status, passando de mortos-vivos a cadáveres, sendo 
enterrados sem dilemas morais. As fronteiras no romance se assemelham aos efeitos dos argumentos construídos e reproduzidos na campanha que se seguiu à redefinição da morte nos anos 1960, nos Estados Unidos, em prol de sua legitimação em território nacional e estrangeiro. Nessa empreitada, o humano é também redefinido e é apresentado em diferentes formas, circunscrito em fronteiras culturais e delimitações forjadas em diferentes campos de conhecimento.

Em outro texto apresento de maneira pormenorizada o desenvolvimento de tecnologias de suporte de vida em meados do século xx que materializou o sonho de estender a vida e conduziu a mais experimentações médicas, a infindáveis debates éticos e novas concepções de ser humano, de morte e de vida (Kind, 2009). Neste trabalho descreve-se a construção de argumentos, o intercâmbio internacional de práticas e ideias e a proliferação de procedimentos médicos que se apóiam em distintas concepções de ser humano. A produção do trabalho se orienta pela composição de certa "anatomia de textos científicos", como alude Latour (2000) em seu convite à análise de processos de produção científica.

Pretende-se analisar um processo de produção científica particular, elegendose textos que permitem identificar derivações da definição de morte cerebral (brain death), a saber, whole brain death, higher brain death e brain stem death. ${ }^{\mathbf{1}}$ Compõem o corpus de análises deste trabalho alguns dos principais textos científicos que fazem parte da rede de produção de fatos médicos que se seguem à definição de morte cerebral no final dos anos 1960. Foram selecionados textos que possibilitam a identificação de um conjunto de elementos envolvidos na produção de fatos científicos, tais como autores e composição de uma rede de colegas, situações específicas, vínculos institucionais, diálogos e debates, consensos e dissensos, dentre outros aspectos. Toma-se um desses textos como ponto de partida, o artigo "A definition of irreversible coma" (Ad Hoc Committee, 1968), pois ele "coloca entre aspas" a definição de morte cerebral, deflagrando extenso processo de discussão que provocou transformações nas práticas médicas e organizou argumentos para sustentá-las que caminharam em direções distintas.

Em 1968, a definição de morte cerebral foi apresentada à comunidade médica estadunidense como algo que merecia ser elevado à condição de fato médico (Ad Hoc Committee, 1968). O artigo "A definition of irreversible coma”, de apenas quatro páginas, é estrategicamente publicado noJournal of the American MedicalAssociation (JAMA), como observa Belkin (2003). No processo de estilização que se originou a partir das afirmações expostas no documento do Ad Hoc Committee, a morte cerebral-brain death,

1 As três principais variações da definição de morte cerebral, whole brain death, brain stem death, e higher brain death, serão mantidas em inglês por não haver consenso sobre a melhor tradução para o português. Além disso, tomadas como qualificações da morte, as expressões whole brain, brain stem e higher brain serão problematizadas ao longo do texto como parte do processo de produção de fatos científicos em torno da definição de morte cerebral. 
como definida originalmente - ganhou contornos específicos ao se agregarem a ela argumentos médicos, jurídicos, filosóficos e políticos ao longo dos anos subsequentes à publicação desse documento.

A publicação do relatório sobre morte cerebral foi antecedida por certa rede de colaboração entre cirurgiões de diversos países que haviam sido treinados para conduzir transplantes cardíacos pela equipe de Norman Shumway, na Universidade de Stanford. Considera-se que essas "trocas internacionais de práticas", parafraseando Bourdieu (2002), ${ }^{2}$ não só difundiram a tecnologia de transplantes em nível internacional, mas também abriram precedentes importantes para que os cirurgiões estadunidenses pudessem finalmente realizar transplantes com seres humanos. CrowleyMatoka e Lock (2006) chamam a atenção para o frequente destaque dado à diferença cultural nos estudos sobre transplante de órgãos. As autoras realçam três questões recorrentes trabalhadas pela antropologia médica que se dedica ao estudo dos transplantes em diferentes contextos: a redefinição da morte; as concepções de corpo, self e identidade; e o comércio de partes do corpo humano.

Mais do que acompanhar a literatura específica da antropologia médica em busca das diferenças culturais apontadas pelas autoras, pretende-se percorrer as redes de argumentações que sustentaram a composição de distintas definições de morte cerebral. A análise da literatura científica sobre o assunto permite afirmar que a promoção das tecnologias de transplantes de órgãos transformou a definição de morte cerebral numa "caixa preta" (cf. Latour, 2000). Nos anos 1970, a morte cerebral se estabeleceu como um fato científico, mais especificamente como um fato médico. Observa-se um processo de estabilização da definição de morte cerebral em publicações estratégicas, nas quais os questionamentos relativos à definição são suprimidos em favor de reiteradas validações, veiculadas em prestigiados circuitos de textos acadêmicos (cf. Kind, 2007).

\section{A REGEPÇÃO ESTADUNIDENSE DA DEFINIÇÃO DE MORTE GEREBRAL}

O que se criou em torno da definição de morte cerebral em meados do século passado é compatível com o que Fleck (1979) define como "coletivos de pensamento" (thought collectives), comunidades intelectuais, com promoção constante de trocas de ideias,

$2 \mathrm{O}$ autor discute, na verdade, a circulação internacional de ideias no campo das ciências humanas, e suas reflexões são feitas quando ele é convidado a inaugurar, na Alemanha, um Centro de Pesquisas sobre a França. As trocas internacionais, no caso da história da morte cerebral, fizeram-se preponderantemente na forma de transmissão de expertise, de know-how, e de argumentos prêt-à-porter sobre as definições de morte que se estabeleceram com maior sucesso. 
que se reproduz através de um "estilo de pensamento" (thought style). Esse coletivo produz um pensamento que circula livremente na sociedade, promovido por atividades científicas. $\mathrm{O}$ autor alerta para a necessidade de se reconhecer a rede de relações que se forma nesse processo. O que se produz nessa construção do fato médico, assinala o autor, é algo que só pode ser avaliado como de autoria coletiva, cujo produto não pertence a nenhum indivíduo em particular. Vários desses elementos apontados por Fleck podem ser identificados no processo de redefinição da morte.

O relatório do Ad Hoc Committee (1968) desencadeou um amplo debate e, supõese, por ter sido publicado num periódico respeitado no campo médico, foi rapidamente "importado" para compor argumentos pró-transplantes. Stevens (1995) coloca em foco a necessidade de aquiescência da nova definição da morte pela opinião pública. Segundo a autora, a comunidade médica estadunidense estava a par da potencialidade de objeção à tecnologia de transplante:

Mais do que uma resposta médica a um problema moral induzido pela tecnologia, “morte cerebral” era um artifício para autoproteção jurídica. Ela foi designada para proteger a medicina profissional da possibilidade do público perceber um potencial conflito de interesses e se alarmar - um conflito entre a responsabilidade do profissional de cuidar de doentes e moribundos e as demandas da pesquisa médica pela obtenção de órgãos para transplante (Stevens, 1995, p. 217).

Numa das primeiras iniciativas de avaliar a opinião pública sobre a então recém-definida morte cerebral, Arnold, Zimmerman e Martin (1968) apontam que os tribunais não reconheciam como mortos aqueles pacientes que mantinham suas funções respiratórias, apesar de inconscientes. $\mathrm{O}$ texto foi publicado apenas alguns meses depois do relatório do Ad Hoc Committee (1968), no mesmo veículo de reconhecido prestígio na comunidade médica, o Journal of the American Medical Association (JAMA). Nele constam as filiações dos autores a importantes instituições hospitalares e acadêmicas. Os autores concluem que duas razões contribuíram para que o diagnóstico de morte penetrasse na discussão pública:

(1) o uso de doadores em transplantes de um único órgão resulta na morte do doador se isso ainda não tiver ocorrido.

(2) o uso de sistemas de suporte de vida suscitam, frequentemente, o questionamento público de como e quando a morte é determinada (Arnold, Zimmerman \& Martin, 1968, p. 1949). 
INTERMITÊNGIAS DA MORTE...

Os autores realizaram entrevistas em profundidade com 21 pessoas e posteriormente conduziram uma pesquisa envolvendo um público total de 112 pessoas. $\mathrm{O}$ artigo indica que o público estava cada vez mais interessado nas formas de determinação da morte, especialmente face à ampla cobertura da mídia de casos de transplante cardíaco. Os autores lamentam, contudo, o fato do público ainda pensar na morte em termos de parada cárdio-respiratória. Eles indicam a necessidade de um movimento de "educação pública" para difusão do conhecimento da morte determinada pelo EEG. Destaca-se ainda, desta avaliação, que o público solicita um consenso sobre as regras de determinação da morte e que considera essa questão, por seu impacto social, não apenas restritamente ligada ao âmbito da medicina, mas como fato de interesse público. Os resultados da investigação levam os autores a concluírem que "um diálogo público pode e deve se tornar um importante instrumento para se desenvolver um clima no qual o progresso médico e o bem-estar da comunidade possam ser maximizados" (Arnold, Zimmerman \& Martin, 1968, p. 1954).

O estudo de Arnold, Zimmerman e Martin (1968), que figura dentre as primeiras publicações que sustentam a definição de morte cerebral, expõe a necessidade de se fazer um apelo ao público leigo em prol da legitimação dos avanços tecnocientíficos da medicina da época, tidos como um progresso diante do qual não se poderia retroceder. Essa ideia de progresso é inerente ao fato científico em construção (cf. Fleck, 1979; Latour, 2000; 2001). Entretanto, na esteira da composição da morte cerebral como fato irrevogável, a questão do que é o ser humano aparece no cerne das controvérsias em muitos momentos e é evocada por diferentes vozes e posicionamentos. Um dos atores contemporâneos do debate sintetiza essa constatação dizendo que "qualquer definição da morte de seres humanos ou pessoas está (...) atada a concepções de humanidade e pessoalidade que vão além da taxonomia biológica e das definições biológicas de vida e morte" (Lizza, 2006, p. 19). Os conhecimentos tecnocientíficos, embora reconhecidos pelos sectários da definição de morte cerebral, são então atravessados pela necessária discussão sobre os limites que caracterizam o ser humano submetido às novas tecnologias.

De modo frequente os debatedores indagam se o que está sob jugo das tecnologias de suporte de vida é realmente uma vida "humana". No alvorecer dos embates pela melhor definição de morte, Collins (1968) avalia que se destacavam duas habilidades significativas no progresso científico da medicina da época. Os médicos tinham evoluído seu know-how técnico de maneira a, por um lado, "sustentar funções vitais essenciais por meios artificiais" e, por outro lado, a "criar um homem híbrido pelo transplante de órgãos". O texto do anestesista, tratando dos limites da responsabilidade no prolongamento da vida, foi lido na $117^{\mathrm{a}}$ convenção anual da Associação Médica Ameri- 
cana, em junho de 1968, e publicado na revista da entidade poucos meses depois da divulgação da definição de morte cerebral. Nele, o autor enaltece os avanços tecnológicos da medicina que tornavam possíveis o prolongamento da vida a limites nunca antes conseguidos, realçando que o problema crucial seria, então, estabelecer um diagnóstico diferencial para a morte. $\mathrm{O}$ autor conclui que "é evidente que o prolongamento da vida e a determinação da morte não são de responsabilidade teológica ou legal, mas claramente uma responsabilidade médica" (Collins, 1968, p. 392). Esse é o acento dado a muitas publicações realizadas em nome de uma das definições de morte cerebral, whole-brain death, que viria a ocupar um lugar central no debate que se seguiu ao relatório do Ad Hoc Committee.

\section{Whole-brain death: A MORTE DO ORGANISMO}

A primeira definição derivada do A definition of irreversible coma (Ad Hoc Committee, 1968) foi a de "morte de todo o encéfalo", ou whole-brain death. Durante pouco mais de uma década após a publicação, essa variação encontrou adeptos que constituíram seu próprio coletivo de pensamento. Defendia-se a bandeira de que essa definição deveria ser reconhecida no âmbito jurídico, apesar da tentativa de reafirmar seu caráter técnico; ou seja, a definição da morte era assunto de competência estrita da medicina. A despeito da participação de outros campos de conhecimento, como a teologia, a filosofia e o direito, para além da grande maioria de médicos que advogavam por essa definição, o ponto central dos argumentos girava em torno da concepção de ser humano como organismo.

Com maior ou menor destaque na literatura sobre whole-brain death, seus defensores preconizam uma definição biológica do ser humano e da morte (cf. Lamb, 1978; Capron \& Kass, 1972; Bernat, Gulver \& Gert, 1981; President’s Commission, 1981a, 1981b; Bernat, 1992, 2002, 2005).

Lamb inicia sua defesa de forma contundente, dizendo que se pode formular "uma definição de morte estritamente biológica, considerada como um evento específico" (Lamb, 1978, p. 144). O neurologista sustenta sua afirmação legitimando o documento do Ad Hoc Committee, considerado por ele como suficiente para delimitar uma nova definição da morte. Em publicação mais recente, o autor destaca o cérebro como órgão "essencial" para se dizer o que é um ser humano:

Um ser humano pode funcionar sem um braço, um coração, se um substituto mecânico estiver disponível, mas a função cerebral é a completude do ser huma- 
INTERMITÊNGIAS DA MORTE...

no. Um ser humano não está completo sem um cérebro, não importa quantos sistemas podem funcionar de maneira independente (Lamb, 2003, p. 163).

Lamb critica formulações contrárias à de whole-brain death, ressaltando o caráter conciliador que a definição tem com a opinião pública, objeto de preocupação de muitos especialistas dedicados ao debate da redefinição da morte.

A defesa da whole-brain death alcançou a legislação estadunidense por meio da mobilização de um conjunto de especialistas organizados em comitês, e de publicações em espaços relevantes do ponto de vista técnico. Essa definição se consolidou no documento produzido pela President's Commission for the Study of Ethical Problems in Medicine and Biomedical and Behavioral Research (1981b). Esse relatório avalia os diversos documentos utilizados para regulamentar a definição de morte cerebral em diferentes estados norte-americanos com a tarefa de fazê-los convergir para um único documento que orientaria, a partir de então, a prática médica e as disputas legais em torno da questão. Resultado dessa análise, o Uniform Determination of Death Act - UDDA (President's Commission, 1981a) "atualizou" a definição de morte cerebral com a delimitação dada em defesa da whole-brain death.

Não obstante o fato de que mais de uma década de polêmica havia transcorrido antes da formação da President's Commission, sua tarefa era apresentada como se não exigisse tanto esforço intelectual quanto parecia. O texto apresenta a questão da definição da morte cerebral, em seus aspectos técnicos e jurídicos, como não sendo "inerentemente difícil ou complicada". Nos termos do documento, trata-se "simplesmente" de decidir "se a legislação deve reconhecer novos meios para se estabelecer que a morte de um ser humano ocorreu" (President's Commission, 1981b, p. 3). O documento apresenta o encargo da Comissão:

Os corpos mantidos artificialmente apresentam uma nova categoria para a legislação (e para a sociedade), para a qual a aplicação de meios tradicionais para se determinar a morte não é nem clara nem inteiramente satisfatória. A incumbência da Comissão é estudar e recomendar caminhos pelos quais os parâmetros legais tradicionais podem ser atualizados de maneira a fornecer orientação clara e fundamentada para se determinar se tais corpos estão vivos ou mortos (President's Commission, 1981b, p. 3).

A preocupação central do relatório é a padronização da definição da morte, com o objetivo de subsidiar decisões legais que tivessem a tarefa de decidir se e quando um ser humano morreu. Em seu processo de avaliação, a comissão ouviu filósofos como 
Daniel Wikler e Robert Veatch, neurologistas, teólogos - como Paul Ramsey ${ }^{3}$ - além de membros da comunidade judaica. Representantes da American Bar Association (ABA), da American Medical Association (AMA) e da National Conference of Commissioners on Uniform State Laws (NCGUSL) também foram ouvidos. A convergência apontada no documento é de que "as testemunhas concordam que os avanços tecnológicos que possibilitaram a respiração artificial também geraram critérios para determinar a parada irreversível das funções cerebrais" (President's Commission, 1981b).

Todavia, dentre as ditas "testemunhas" consultadas, os médicos é que indicam a necessidade de uma definição de morte legalizada que tenha como parâmetro a parada irreversível das funções cerebrais. Assinala-se que "manter um corpo morto em sistemas de suporte artificial consome recursos médicos escassos e pode desnecessariamente exaurir os recursos emocionais e financeiros dos familiares" (President's Commission, 1981b, p. 10).

Entre os teólogos ouvidos, o documento destaca o Padre Quay e Paul Ramsey, que advertem que uma redefinição da morte regulamentada em lei não deveria ser precipitada pela necessidade de suprir a carência de órgãos para transplantes.

Ao descrever o significado da morte, o relatório aponta três órgãos como essenciais para se determinar quando ela ocorre: o coração, os pulmões e o cérebro. O destaque dado a esses órgãos e a discussão técnica de sua interconexão para manter o organismo vivo "como um todo" acabou por compor uma convergência de argumentos para consolidar o que viria a ser apresentado no UDDA como duas possibilidades de morte.

\section{(...) A morte é aquele momento no qual o sistema fisiológico do corpo deixa de se configurar como um todo integrado. Mesmo se a vida continua em células ou ór- gãos isolados, a vida do organismo como um todo requer uma integração com- plexa e, sem a última, uma pessoa não pode ser apropriadamente considerada viva (President's Commission, 1981b, p. 33).}

A conclusão apresentada no documento, apesar da multiplicidade de opiniões frente à redefinição de morte e sua funcionalidade para o transplante de órgãos, é in-

\footnotetext{
3 Em seu clássico Patient as a person, publicado em 1970, Ramsey parece aderir a uma definição organicista de ser humano afirmando que "a vida significa o funcionamento do ser integrado ou do organismo fisiológico como, em algum sentido, um todo” (p. 59). No centro de seus argumentos está sua preocupação de que a redefinição da morte seja imposta por uma exigência da tecnologia de transplantes e de defesa exaustiva por parte dos médicos. Estes são acusados por Ramsey de se preocuparem exclusivamente com a tentativa de encontrar um procedimento de consenso para afirmar, sem consequências jurídicas, que um ser humano está morto. Por suas colocações, Ramsey é associado por Lizza (2006) aos defensores da definição de whole-brain death, sem levar em conta sua posição como "testemunha” contrária à formulação apresentada no Relatório da President’s Commission.
} 
cisiva, não deixando sombra de dúvidas sobre seu posicionamento a favor da definição de whole-brain death .

Pernick (1999), historiador da medicina, acusa a President's Commission de não ter questionado a autoridade médica a respeito da redefinição de morte, atribuindo apenas a esta ciência o direito de atestar quem e quando está vivo ou morto. Na verdade, à exceção de alguns teólogos, ninguém questionou, nem mesmo o Papa Pio XII 4 quando foi convocado a conversar com representantes da comunidade médica. Mesmo aqueles considerados outsiders por Pernick - os não-médicos que entraram no embate - aproximaram-se de critérios e discussões característicos da medicina, mais especificamente da neurologia. Para os defensores da "morte de todo o cérebro", wholebrain death, uma justaposição vai aos poucos se formando entre o ser humano e o cérebro, ganhando o último o status de representante, por excelência, do primeiro.

O Relatório da President's Commission reproduz a dimensão estatutária da definição de morte cerebral defendida por Capron e Kass (1972). A publicação da "Proposta Capron-Kass" foi decisiva para o desenvolvimento do raciocínio médico-legal sobre a morte cerebral. Os autores discutem a morte cerebral através de sua aproximação com o direito, atualizando estatutos em vigor à época em alguns estados norte-americanos, mas também sustentam seus argumentos a partir da delimitação do que compreendem por "pessoa" ou "ser humano". O artigo é anunciado como fruto dos esforços de discussão do Grupo de Pesquisa sobre a Morte e o Morrer (Research Group on Death and Dying), coletivo de pensamento engajado na redefinição de morte, em torno de uma necessária revisão da definição de morte em prol do "bom uso de órgãos de corpos mortos" mantidos artificialmente. O Grupo foi gerado do desdobramento da forçatarefa sobre a morte e o morrer (Task Force on Death and Dying), que se constituiu como fórum privilegiado de encontro e embate na produção da definição de morte cerebral. O texto de Capron e Kass (1972) se destaca, portanto, como importante peça na pilha de referências sobre a morte cerebral, repercutindo na rede de documentos científicos como portador de dupla relevância; a saber, o mérito de se configurar como discussão científica e, ao mesmo tempo, de poder ser utilizado como substrato jurídico para a redefinição da morte. Posteriormente, o artigo-documento foi reconhecido pela President's Commission (1981b) como um modelo estatutário contribuindo para a con-

4. O Papa Pio xII foi convidado pela comunidade de anestesiologia dos Estados Unidos para responder questões morais a respeito do prolongamento da vida possibilitado pelas novas tecnologias de suporte da vida. Em 1957 o pontífice proferiu a conferência que ficou conhecida como The prolongation oflife. Dentre outros aspectos, ele enuncia que "compete ao médico, em particular ao anestesiologista, produzir uma definição clara e precisa da 'morte' e do 'momento da morte' de um paciente que falece em estado inconsciente" (Papa Pio xiı, 1957, p. 1031). Outros pontos sobre essa conferência são encontrados em Kind (2009). 
solidação do hábito de pensamento da morte cerebral como questão de competência da ciência médica, validada pelas instâncias legais.

Em acréscimo ao Definition of irreversible coma (Ad Hoc Committee, 1968), o Statutory definition of the standards for determining human death de Capron e Kass (1972) adota categoricamente a necessidade de obtenção de órgãos para transplantes como justificativa suficiente para o reconhecimento da nova definição de morte. O primeiro documento encontrou a desconfiança pública, dada a curta sobrevida dos primeiros pacientes submetidos a transplante cardíaco, vítimas quase certas da rejeição, na década subsequente ao procedimento pioneiro de Barnard. Já a publicação de Capron e Kass (1972), como base para o relatório da President's Commission (1981b), tinha a seu favor o sucesso dos imunossupressores utilizados no final dos anos $1970 \mathrm{em}$ animais, com respostas animadoras para combater a rejeição de órgãos e tecidos. 5 Nos anos 1980, com o uso das drogas contra a rejeição de órgãos em seres humanos, foi vencida uma barreira técnica importante para a concretização do transplante cardíaco como procedimento regular, livrando-o da marca de experimentação dos anos iniciais. Nesse clima favorável, a dupla composta por um advogado - Capron - e um médico, doutor em bioquímica - Kass -, pôde afirmar, sem rodeios, que uma das principais finalidades da definição estatutária de morte cerebral era a necessidade de se obter órgãos em boas condições para transplantes.

Sobre a questão do debate público, os autores concluem que, apesar da necessária liderança da ciência médica para a validação de um padrão aceitável de determinação da morte, representantes da opinião pública devem participar da construção de novos critérios dessa redefinição. Contudo, eles distinguem duas maneiras de participação do público, sendo a primeira uma ampla divulgação e estímulo ao debate em torno da questão, orientada por entidades médicas. A segunda forma assinalada endereça ao sistema judiciário, por seu caráter de confiabilidade e autoridade pública, a tarefa de encontrar uma posição de consenso entre a legislação e os processos derivados de casos de morte cerebral. Capron e Kass (1972) reivindicam, dessa forma, a sintonia entre os tribunais e a legislação, convocando o coletivo dos Commissioners on Uniform State Laws para liderar o debate - e consequente consenso - no campo jurídico.

Os autores se contrapõem à primeira iniciativa de definição legal de morte cerebral presente no Estatuto do Kansas, estado norte-americano pioneiro em agregar critérios neurológicos para definição da morte a suas leis. Esse documento delimita, na opinião de Capron e Kass (1972), dois tipos diferenciados de morte. Eles citam o texto em dois parágrafos do Estatuto do Kansas, intitulado An act relating to and defining death,

5 DiBardino (1999) aponta a gradual mas entusiástica incorporação de imunossupressores ao tratamento da rejeição de órgãos e tecidos na década de 1980, considerada pelo autor como a era moderna do transplante de órgãos. 
no qual a pessoa é considerada morta por parada cardio-respiratória, em condições nas quais as iniciativas de ressuscitação são consideradas inúteis, ou por "ausência de funções cerebrais espontâneas". Como contraponto ao documento do Kansas, os autores propõem sua própria definição de "morte de uma pessoa", que julgam ser mais apropriada, uma vez que não se desdobraria em duas e poderia ser aplicada universalmente a todos os seres humanos. No cerne de sua proposta de estatuto, os autores apresentam sua definição de morte "aceitável".

Uma pessoa será considerada morta se, na opinião declarada de um médico, baseado em procedimentos ordinários da prática médica, ela experienciou uma parada irreversível das funções espontâneas da respiração e da circulação. No caso em que meios artificiais de suporte impedem a determinação de que essas funções cessaram, uma pessoa será considerada morta se, na opinião declarada de um médico, baseado em procedimentos ordinários da prática médica, ela experienciou uma parada irreversível das funções espontâneas do cérebro. A morte terá ocorrido no momento em que as funções relevantes cessaram (Capron \& Kass, 1972, p. 111; grifos meus).

A definição de Capron e Kass tem o mérito de unir as duas definições de mortepor cessação das funções cardio-respiratórias ou cerebrais. Eles deixam em aberto a destinação do corpo da pessoa que morre.

A referência explícita ao transplante de órgãos manteve-se como problema ético nos documentos posteriores à "Proposta Capron-Kass", aí incluídas as publicações da President's Commission (1981a; 1981b), que consolidaram a definição da "morte do cérebro como um todo" como equivalente de morte cerebral. A partir dessas publicações a formulação de whole-brain death ganhou proeminência como estilo de pensamento, tanto em manifestações favoráveis quanto contrárias à definição. Assim, whole-brain death tornou-se ponto de partida para as discussões posteriores de morte cerebral, mesmo quando emergiam variações em sua descrição ou contrapontos desencadeando outras definições, como será abordado adiante.

Contudo, Capron e Kass não foram os únicos a contribuírem para a delimitação dessa definição de morte cerebral. Enquanto eles se interessavam por uma clara delimitação estatutária para a definição da morte, Bernat, Gulver e Gert (1981) dedicaram-se a fortalecer a ideia de pessoa como "um organismo", atrelada, portanto, a uma concepção biológica de ser humano. Em artigo bastante mencionado em toda a bibliografia sobre morte cerebral, os autores defendem as premissas de uma definição consensual de morte na qual "a perda total e irreversível das funções de todo o cérebro" deve figurar como o "único critério de morte”. Os autores, neurologista, psiquia- 
tra e filósofo, respectivamente, propõem que é preciso distinguir a definição da morte dos critérios médicos para essa definição e os testes necessários para confirmá-la. Em suas palavras:

Produzir a definição é principalmente uma tarefa filosófica; a escolha do critério é primordialmente médica; e a seleção dos testes para provar que o critério é satisfatório é exclusivamente um assunto médico (Bernat, Culver \& Gert, 1981, p. 389).

Os autores seguem um princípio perpetuado pelos adeptos da definição de wholebrain death, que é circunscrevê-la à competência médica. Quanto à primeira tarefa, os autores sustentam que uma boa definição de morte deve entendê-la como algo que ocorre num momento mais ou menos preciso, e não como um processo.

Se considerarmos a morte como um processo, então ou o processo começa quando a pessoa está ainda viva, o que confunde o "processo de morte" com o processo do morrer, pois todos consideramos que uma pessoa que está morrendo ainda não está morta, ou o "processo da morte” se inicia quando a pessoa já não está viva, o que confunde a morte com o processo de desintegração. A morte não deveria ser vista como um processo, mas como um evento que separa o processo do morrer do processo de desintegração (Bernat, Culver \& Gert, 1981, p. 389).

Continuando sua linha de raciocínio, os autores consideram a expressão "morte de uma pessoa", frequentemente apresentado nas discussões sobre a definição da morte cerebral, como um recurso metafórico. Em contraposição, eles defendem que o que morre é o organismo.

O conceito de "pessoa” não é biológico, mas, ao contrário, é um conceito definido em termos de certos tipos de habilidades e qualidades de consciência. Ele é inerentemente vago. Morte é um conceito biológico. Dessa forma, de maneira literal, a morte pode ser diretamente aplicada apenas a organismos biológicos, não a pessoas (Bernat, Gulver \& Gert, 1981, p. 390).

Mesmo tendo entre eles um filósofo, esses autores insinuam a fragilidade da "pessoa", localizando o ser humano como espécie. Consequentemente, sua morte é a morte de um organismo como outro qualquer. Nas palavras dos autores, "quando falamos da morte de um homem queremos dizer a mesma coisa de quando falamos da morte de um cachorro ou de um gato" (Bernat, Gert \& Culver, 1981, p. 390). 
INTERMITÊNGIAS DA MORTE...

Apesar de considerarem a consciência e a cognição como atributos essencialmente humanos, os autores alertam para a necessidade de não se confundir "a morte de um organismo que era uma pessoa" com a pessoa deixando de existir no organismo (Bernat, Culver \& Gert, 1981, p. 391). Sendo assim, "um paciente [conectado] a um ventilador com o cérebro totalmente destruído é meramente um grupo de subsistemas artificialmente mantidos já que o organismo como um todo parou de funcionar" (p. 391).

Dessa constatação os autores pleiteiam a perda do funcionamento do cérebro como um todo como o critério suficiente para a definição da morte e que os testes deveriam, portanto, verificar a ausência de funcionamento cerebral, com destaque para o EEG isoelétrico ou de traçado plano. Sem detalhar os testes, os autores alertam para o cuidado de se utilizar apenas instrumentos validados pela prática médica.

Duas décadas após a publicação com seus colaboradores, Bernat (1992; 2002) continuou sendo porta-voz da definição que se tornou hegemônica nos Estados Unidos. Em 1992, o neurologista publicou sua reafirmação da definição de whole-brain death, sustentando que "a morte é melhor definida como a parada permanente do funcionamento do organismo como um todo" (Bernat, 1992, p. 24).

Bernat critica as teses construídas em defesa da higher brain death e da brainstem death, que serão discutidas em detalhe adiante. Quanto à primeira definição, cujo argumento central é que a morte da pessoa ocorre quando se ausenta aquilo que é necessário para identificá-la como tal - a consciência -, o autor questiona a confiabilidade de se fazer seu diagnóstico. Ele confirma sua convicção de que a morte não passa de um conceito biológico regular, contrapondo-se à definição dependente da consciência. Para ele:

A formulação da “morte do tronco encefálico" pertence não à definição da morte, mas à definição de perda de pessoalidade (personhood). Ao contrário da morte, que é um fenômeno biológico, a pessoalidade é um conceito psicossocial e espiritual, incorporando certas qualidades de consciência, de personalidade e de identidade. Os pacientes apenas com destruição neocortical perderam sua pessoalidade, mas permanecem vivos, pois a maioria das funções de seu organismo como um todo estão intactas (Bernat, 1992, p. 23).

A defesa contundente do neurologista permanece no debate mais recente e levao a propor um "paradigma da morte" que se apoia em premissas que ele nomeia como "bases biofilosóficas" da whole-brain death (Bernat, 2002). Ao longo da listagem das bases biofilosóficas, Bernat vai tecendo seu argumento principal de que a "morte é um conceito biológico". A dimensão "filosófica" de suas proposições aparece de maneira secundária, sempre em oposição a pressupostos de outras frentes de defesa à higher 
brain death e à brainstem death. Sua proposição mais incisiva é de que é possível localizar, na whole-brain death, ou seja, na "perda permanente da capacidade do organismo funcionar como um todo" (p. 334), o "sistema crítico" sem o qual o organismo não pode ser identificado como um ser humano. Nas palavras do neurologista: "A morte é definida como a parada permanente das funções críticas do organismo como um todo. (...) O cérebro é o sistema crítico do organismo sem o qual este não pode funcionar como um todo" (Bernat, 2002, p. 335).

O cérebro, nessa perspectiva, é o único sistema "insubstituível”, que apenas em ficções científicas poderia ser transplantado. Uma vez localizado o sistema crítico sem o funcionamento do qual o organismo está morto, a definição whole-brain death ganharia longevidade sobre as outras. A permanência dessa definição, assegura Bernat (2002), supera até mesmo futuros avanços tecnológicos, visto que o sistema crítico a ela atrelado jamais será passível de reposição.

A oposição entre as definições de whole-brain death e higher brain death se baseia em suas teses fundadas na neurologia e na filosofia, respectivamente, e toma a cena em solo estadunidense. A definição de brainstem death, mais próxima de uma variação da primeira, também se apoia no campo da neurologia, tendo como especificidade com relação à whole-brain death o entendimento de que a destruição irreversível do tronco cerebral é condição necessária e suficiente para a que o organismo pare de funcionar como um todo. Essa definição se consolidou no Reino Unido, graças a Gristopher Pallis, neurologista célebre por sua defesa do diagnóstico de brainstem death.

\section{A ALTERNATIVA DA brainstem death EM TERRAS ESTRANGEIRAS}

No início dos anos 1980, Pallis publicou uma série de pequenos artigos como reação ao programa da BBC sobre transplantes de órgãos, Panorama, que foi nomeado por Gray (2002) como um "amontoado de imprecisões" (farrago of innacuracy). Jennett e Hessett (1981) relatam o impacto do programa na então promissora agenda de transplante renal de doadores cadáveres.

A confiança que foi vagarosamente construída em anos recentes entre o público, o médico do doador e o cirurgião de transplantes foi, entretanto, temporariamente solapada pelo comentário equivocado no Panorama da BBC em outubro de 1980. O programa “Transplantes - os doadores estão realmente mortos?" provocou uma tempestade na imprensa aberta e na médica e as semanas posteriores presenciaram uma redução considerável em doações de órgãos. As dúvidas a respeito da confiabilidade dos critérios para diagnóstico de morte cerebral foram 
INTERMITÊNGIAS DA MORTE...

atualmente resolvidas e o nível de doações de órgãos está sendo gradualmente restaurado (Jennett \& Hesset, 1981, p. 359-60).

Na defesa feita no British Medical Journal, Pallis delimita as características clínicas da brainstem death. No artigo "Medicine and the media" (1980), o neurologista responde diretamente ao Panorama, que trouxe casos de pacientes americanos diagnosticados com brain death que se recuperavam e contavam suas "histórias de terror". Pallis utiliza o programa para, ao mesmo tempo, colocar em questão a definição e os testes de morte cerebral praticados no Reino Unido e criticar a pretensão da mídia que não convocava especialistas, pretendendo ser, ainda assim, levada a sério. Dois documentos, produzidos na Conference of Medical Royal Colleges, nos anos 1970, são mencionados por Pallis (1982b) como o "código do Reino Unido". O primeiro deles, produzido em 1976, reconhece a brainstem death como forma válida de morte cerebral, e o segundo memorando, de 1979, a equivale à morte humana.

Semeada a possibilidade de rever os critérios de morte cerebral, a convite do British Medical Journal (BMJ), Pallis publicou a série intitulada ABC of brainstem death, ${ }^{6}$ cujos artigos discutem a definição, os testes e o impacto da brainstem death do ponto de vista médico, jurídico e social. Ele introduz a questão dizendo que "os constrangimentos legais e as definições de dicionário provavelmente atrasaram a aceitação da noção da morte como um processo" e que "um cérebro morto num corpo cujo coração continua pulsando é um dos mais macabros produtos da tecnologia moderna" (Pallis, 1982a, p. 14,09). A definição da brainstem dead é formulada no primeiro artigo da série do BMJ em contraposição à whole-brain death.

Eu concebo a morte humana como um estado no qual há a perda irreversível da consciência combinada com a perda irreversível da capacidade de respirar (e, consequentemente, de manter o coração). Sozinha, nenhuma seria suficiente. Ambas são essencialmente funções do tronco encefálico (...). O conceito é admitido como híbrido, expressando tanto atributos filosóficos quanto fisiológicos. (...) A morte do tronco encefálico é a essência fisiológica da morte cerebral, o substrato anatômico de seus sinais básicos (coma apnéico com ausência de reflexos do tronco encefálico) e a principal determinante de seu invariável prognóstico cardíaco: assístole em algumas horas ou dias (Pallis, 1982a, p. 1410-2).

6 Os artigos (1982a, 1982 b, 1982c, 1982 d, 1982e, 1983a, 1983b, 1983c, 1983d) são versões resumidas do livro publicado em 1983 com o mesmo título da série (Pallis, 1983e). As contribuições de Pallis foram ampliadas em segunda edição do $A B C$ of brain stem death, publicado em colaboração com Harley (Pallis \& Harley, 1996). 
Nesses breves artigos o neurologista apresenta testes necessários para se diagnosticar a perda irreversível da morte do tronco cerebral (Pallis, 1982c; 1982d; 1982e). Pallis indica que essa avaliação é clínica, feita a partir de testes simples, alguns ilustrados no texto com desenhos esquemáticos, assim como o padrão para avaliação da morte cardio-respiratória. O neurologista ironiza a suposição veiculada no Panorama de que pacientes diagnosticados com morte cerebral, portanto, potenciais doadores, eventualmente poderiam se recuperar, anunciando que "o primeiro paciente a falar novamente após ter mostrado sinais inequívocos da morte do tronco encefálico criará uma sensação tão grande quanto se a cabeça decapitada de Luis xvi tivesse começado a amaldiçoar seus executores" (Pallis, 1982e, p. 1644). A ligação entre a definição de morte cerebral proposta por ele e o transplante de órgãos, ao contrário da postura assumida por seus colegas norte-americanos, é feita sem subterfúgios.

Se [os testes confirmarem] um tronco encefálico morto, a morte deve ser declarada, os parentes notificados, e um conseguinte registro apropriado deve ser feito. Um paciente está morto quando um médico (utilizando critérios consensuais) o declara morto. (...) Se o transplante é planejado, o "cadáver com batimentos cardíacos” deve ser reconectado ao ventilador (Pallis, 1983a, p. 39).

No debate proposto por Youngner, Arnold e Schapiro (1999) sobre as controvérsias contemporâneas a respeito da morte cerebral, Pallis (1999) reage aos comentários de Brody (1999), que assina artigo precedente ao seu na mesma coletânea. Brody afirma que tanto a definição de morte cerebral legitimada nos Estados Unidos (whole-brain death) quanto a do Reino Unido (brainstem death) são formas de garantir a retirada indiscriminada de órgãos para transplante. Pallis se contrapõe a esse argumento insistindo que, apesar de concordar que a morte é um processo, e não um evento, há pontos sem retorno no morrer. Ao se confirmar o diagnóstico de brainstem death, insiste o neurologista, os respiradores artificiais estariam "ventilando cadáveres".

A principal crítica feita a Pallis é a de que sua definição e seus critérios levariam com frequência à "síndrome do encarceramento" (locked-in syndrome), condição clínica em que o paciente se mantém consciente e alerta, a despeito da completa ausência de movimentos (Brody, 1999; Bernat, 1992). Apesar das críticas, Pallis encontra menos resistências às suas formulações no Reino Unido do que seus colegas submetidos à legislação e à opinião pública estadunidenses. Nos Estados Unidos, a consciência como noção relevante para a redefinição de morte foi descartada nos documentos e procedimentos oficiais. Ainda assim, isso não impediu que argumentos fervorosos fossem construídos nessa direção, como discutiremos adiante. 
INTERMITÊNGIAS DA MORTE...

\section{Higher brain death: QUANDO A CONSGIÊNGIA SAI DE GENA}

Uma última definição que merece ser resgatada e discutida é a higher brain death, pelo caráter polêmico das discussões que suscita. Enquanto para os defensores da wholebrain death os critérios e argumentos médicos parecem ser mais relevantes na definição da morte, argumentos teológicos e filosóficos são preponderantemente arregimentados para sustentar as formulações relacionadas à higher brain death. Nelas, mais importante do que delimitar o que é um "organismo vivo" ou quando e como ele morre, é estabelecer o que há de "humano" naquele que morre. A "pessoalidade" (personhood) ou "humanidade" (humaness) ganham destaque na definição da morte. A partir da delimitação dessas "essências da pessoa" é que se poderia dizer o que ou quem está vivo ou morto.

Encontramos diferentes acentos no que se entende como aquilo que é "essencial" para caracterizar a pessoalidade ou humanidade ao analisar as divergências entre os próprios adeptos da higher brain death. Lizza (2006) aponta que há posições distintas entre os defensores dessa tese em suas variadas maneiras de vincular a consciência à morte cerebral, destacando-se as proposições de Robert Veatch (1976; 1999), de Green e Wikler (1980) e dele próprio.

Robert Veatch foi o idealizador da definição de higher brain death, inicialmente apresentada em 1975, quando encabeçava o "Grupo de Pesquisas sobre a Morte e o Morrer" do Hastings Center (Veatch, 2003). Desde sua publicação clássica, Death, dying and the biologocial revolution (1976), reeditada no final dos anos 1980, ele defende de forma acirrada sua formulação, guiado pela premissa de que a questão sobre o que é essencial para se identificar um ser humano deve se fundamentar por pressupostos filosóficos. Na versão de 1989 do livro, Veatch incorpora sua reação à crítica feita pela President's Commission (1981b), apontada anteriormente, de que a higher brain death depende da noção de pessoalidade para se sustentar. $\mathrm{O}$ autor parece não considerar isso um problema, assumindo que os conceitos de vida e de morte relacionados a um ser humano são mutuamente excludentes; ou a pessoa deve ser tratada como morta ou como viva. Sua defesa é por uma mudança da definição de morte que incorpore a consciência com o ponto crucial para se determinar se um ser humano está vivo ou morto.

Em resposta à crítica da President's Commission (1981b), Veatch (1989) avalia apenas a definição de whole-brain death, terá espaço de consenso nas políticas públicas sobre a morte. Ao identificar a dificuldade que outras definições encontrariam na busca de consensos, ele advoga que cada um deveria escolher a definição que lhe for mais conveniente. Além disso, Veatch se dedica a desconstruir a ideia de que a morte se manifesta em um "lugar" privilegiado do corpo humano, indagando seus interlocutores sobre para onde se deveria “olhar” para verificá-la. Para ele, diferentes localizações para a morte acompanhariam concepções distintas sobre ela. 
A discussão sobre a localização da consciência é uma réplica à tentativa da President's Commission de tentar associar a higher brain death com as palavras "cerebral" (cerebral), "cortical" e "neocortical”, e de agregar a formulação ao discurso neurofisiológico que, de acordo com Veatch, deve ser evitado. Para se defender dos termos que ligam a higher brain death à noção de pessoalidade, Veatch $(1988,1989)$ censura os argumentos de Green e Wikler (1980) sobre a identidade pessoal, acusando esses autores de ter uma "visão extremamente modesta do status ontológico dos julgamentos morais" (Veatch, 1989, p. 27). Eles estariam errados em associar identidade pessoal e morte, pois a fragilidade desse argumento estaria em sustentar que há "continuidade de si mesmo" (sameness), uma concepção lockeana, em situações de perda da consciência, o que coloca os autores diante de questões éticas não necessariamente associadas à morte. O autor se diferencia de Green e Wikler (1980), cujos argumentos serão analisados em detalhe adiante, dizendo que a posição deles é passível "de todo tipo de críticas que sugerem que um ser humano que perdeu sua pessoalidade ou sua identidade pessoal pode, não obstante, ainda estar vivo" (Veatch, 1988, p. 179).

Veatch $(1988,1989)$ alega que não se pode pensar na continuidade ou não da pessoalidade ou da identidade pessoal como morte, pois pode haver situações em que esse aspecto não se mantém, como nas demências ou amnésias decorrentes de lesões cerebrais, por exemplo. Nesses casos, sempre se pode argumentar que uma pessoa pode se tornar "outra”, pode construir outra história de vida totalmente distinta.

Apesar das críticas a ele direcionadas, passadas três décadas de sua delimitação da higher brain death, Veatch (2005) continua fiel à definição, agregando à tese da consciência, que mantém seu lugar de destaque, a necessidade de "plena estabilidade moral" (full moral standing).

Pessoas que normalmente percebemos como sendo seres humanos vivos são vistos, algumas vezes, como possuidores de um status moral diferenciado. Isso pode ser chamado de "plena estabilidade moral". Esse é um status que apreendemos como pertencente ao conjunto dos membros da comunidade moral humana. (...) No início dos anos 1960 nós atribuímos uma expressão [morte cerebral] àqueles que perdiam a "plena estabilidade moral". Tomando uma expressão que originalmente tinha um significado bem diferente, chamamos esses indivíduos de "mortos". (...) Assim, chamar alguém de "morto" tem pouco ou nada a ver com a forma como utilizamos os termos "vivo" ou "morto" na biologia. Tem tudo a ver com o status moral (e legal) (Veatch, 2005, p. 359).

Permanece em suas considerações o enfrentamento das teses e documentos da whole-brain death, tachando-a como "fundamentalismo biológico". Veatch (2005) acusa 
Shewmon e outros autores contrários aos critérios neurológicos para definição da morte de "somaticistas" (somaticists), em função da defesa que fazem de que o cérebro não é o responsável único pela integração somática do indivíduo. Shewmon (2001) questiona, por sua vez, os "essencialismos" das teses preponderantes no debate sobre a redefinição da morte: o "essencialismo biológico" dos defensores da whole-brain death e o "essencialismo psicológico", dos defensores da higher brain death.

O que se ataca por "essencialismo psicológico" pode ser encontrado nos argumentos de Green e Wikler (1980), também defensores de uma definição de higher brain death com contornos próprios. Os autores partem da hipótese ontológica de que a essência do ser humano se localiza no cérebro. Argumentos dessa natureza forneciam razões suficientes, sustentavam os autores, para que os pacientes com morte cerebral fossem reconhecidos como mortos de facto, além de defender o transplante como um "dom da vida" (gift of life), um presente inigualável.

Green e Wikler tentaram desconstruir conjuntos de argumentos clássicos até aquele momento, buscando conferir clareza para a definição de morte cerebral como a morte da pessoa. Os autores apontaram, em primeiro lugar, os "argumentos biológicos", inspirando debates que se centravam nos critérios de definição de morte pela atividade cerebral. Para os autores, esse conjunto de argumentos só serviria para localizar o debate em termos técnicos e proliferar concepções distintas de morte cerebral, como a brainstem death e a whole-brain death, obliterando o esclarecimento se a pessoa estaria ou não morta com a cessação do funcionamento cerebral. Os autores destacam a fragilidade de se considerar a morte cerebral apenas em seu aspecto somático, considerando a falta de precisão nos critérios. Condenam ainda a condição, nesse âmbito, de que o diagnóstico seja restrito ao reconhecimento de especialistas, ilhado no campo médico.

Um segundo conjunto, nomeado como "argumentos morais", situa a morte como um evento cultural e moral, muito além de sua dimensão biológica. Esses argumentos estariam preocupados com o valor da vida. Os filósofos sustentam que essa vertente de argumentos institui consequências desastrosas, na medida em que assume que a vida deve ser mantida a qualquer custo. Em alguns casos, a vida humana perderia seu valor bem antes da morte cerebral, bombardeiam os autores. Para eles o dilema moral entre manter medidas terapêuticas extremas para pessoas mortas e preservar a vida é equivocado. A questão para esses autores passa pela aceitação de "que definir a morte é uma tarefa diferente daquela de decidir quando é o melhor momento de retirar os aparelhos de suporte da vida" (Green \& Wikler, 1980, p. 117).

O terceiro conjunto de argumentos que constituem a hipótese dos autores é nomeado como "argumentos ontológicos". A base da ontologia proposta é a "teoria correta da identidade pessoal" (p. 119; grifo meu), leia-se, aquela inspirada no capítulo xxviı do livro iı dos Ensaios sobre o entendimento humano de John Locke. Ao abordar a pers- 
pectiva lockeana, os autores sustentam que a continuidade de algumas características psicológicas essenciais de um dado indivíduo, num certo intervalo de tempo, comporia o que se pode chamar de identidade pessoal. A fórmula ontológica defendida pelos autores, recorrendo aos argumentos delineados no final do século xvir, é que o cérebro é a sede da identidade pessoal. Um cérebro morto, portanto, enfatizam os autores, "serve apenas para adicionar massa ao corpo se deixado intacto" (Green \& Wikler, 1980, p. 127).

Essa é a concepção extrema que vai sendo construída no campo da definição de morte cerebral e do transplante de órgãos, apoiando-se no argumento antropológico que consiste em assumir que o self é o cérebro. ${ }^{7}$ Tal síntese encontra respaldo no argumento lockeano de que a identidade pessoal é garantida pela consciência. A consciência, e somente ela, constitui a identidade pessoal. A substância viva tem a sua identidade constituída por um senso de continuidade (sameness). Assim, mesmo se modificando ao longo do ciclo de vida, um bebê e um adulto poderiam ser tomados como a mesma substância, se representassem os extremos de uma mesma vida. Nas palavras de Locke:

Isso [a continuidade] demonstra também em que consiste a Identidade de um mesmo homem, a qual nada mais é do que a comunhão da mesma Vida contínua através das partículas contínuas e transitórias de matéria, que numa sucessão estão unidas na vitalidade ao mesmo corpo organizado (Locke, 1999, p. 438).

O "senso de si mesmo" afiançado pela consciência justifica, no contexto da discussão sobre morte cerebral, expressões como "perda irreversível da consciência", tema ao qual voltaremos ao longo do texto. A consciência de si, portanto, configura-se como condição única para se identificar como pessoa. Mas o que dizer de situações em que o sujeito não está "consciente" como essa descrição exige? E se a continuidade de racionalidade se esvai por condições clínicas? O critério de permanência da consciência de si poderia ser o mesmo para um paciente com morte cerebral e para um paciente com Alzheimer? Indagações como essas são enfrentadas em defesas mais recentes da definição de higher brain death.

7 Estudos recentes têm se dedicado a problematizar os efeitos da localização do self no cérebro. Em seus resultados esses trabalhos apontam a noção de sujeito cerebral como leitura crítica na análise do impacto das neurociências na contemporaneidade. Além das discussões de Vidal (2005, 2009) e Ortega e Vidal (2007), outros autores discutem a interpenetração das neurociências em outros campos de conhecimento. Confira a reflexão de Ehrenberg (2004) sobre a guerra entre "sujet cérébral" e "sujet parlant" analisando o "programa forte das neurociências". Mesmo não partindo de uma ideia de sujeito cerebral, vale conhecer também a crítica à "neurofilosofia" apresentada por Andrieu (1998). A própria definição de morte cerebral se sustenta nas baterias de testes neurológicos, na construção de critérios uniformes e na paulatina reificação da pessoa reduzida ao seu cérebro. 
INTERMITÊNGIAS DA MORTE...

Nessa direção, John Lizza, filósofo norte-americano, faz ecoar algumas das principais teses de Veatch. O autor faz uma ampla revisão da literatura sobre morte cerebral, atualizando pontos nevrálgicos do debate. Lizza (2006) é um dos defensores da higher brain death, pleiteando em diversos pontos de sua argumentação que pacientes em estado vegetativo persistente não devem ser considerados pessoas, mas "corpos respirantes".

O autor apresenta sua versão contemporânea do debate em torno da morte cerebral, sintetizada numa pergunta que atravessa sua argumentação: "por que não consideraríamos 'mortos' indivíduos a quem falta potencial para a consciência, o pensamento, o sentimento e cada uma das outras funções mentais?” (Lizza, 2006, p. 1). O filósofo distingue o estado vegetativo "permanente" como "casos extremos de estado vegetativo persistente (PVS), nos quais o diagnóstico da perda irreversível da cons ciência e outras funções cognitivas pode ser determinado com alto grau de probabilidade" (p. 182). Em outras palavras, o que é alvo do debate na atualidade são menos os "brain dead patients", ou pacientes diagnosticados com morte cerebral, mas a extensão desta condição a outros pacientes como bebês anencéfalos e pacientes em estado vegetativo persistente. Lizza (2006) sustenta que "anencéfalos e indivíduos em estado vegetativo permanente são meros corpos respirantes" (Lizza, 2006, p. 12; grifos meus). O que se teria nessas condições seriam outras formas tais como "humanóides" ou "artefatos biológicos".

Encontra-se, nos debates expostos, o emprego da terminologia mais apropriada para nomear os sujeitos diagnosticados com morte cerebral. Como um resultado de lidar com as fronteiras entre a vida e a morte, a definição de morte cerebral e sua tecnologia mais diretamente correlata, o transplante de órgãos, produziu novos "artefatos médicos - corpos mortos com partes vivas, corpos vivos com partes de mortos" (Richardson, 1996, p. 90).

\section{Considerações finais}

$\mathrm{O}$ artigo resgatou alguns meandros das publicações em torno de diferentes definições de morte cerebral construídas ao longo de três décadas. Foram aqui destacados alguns fios da complexa teia de textos sobre morte cerebral publicados em forma de artigos e coletâneas legitimadas pela comunidade científica. Desde 1968, com a publicação do A definition of irreversible coma, o nada ingênuo Comitê ad hoc da Harvard Medical School, agregado pela tarefa de "examinar a definição de morte cerebral", deflagra-se um lento processo de construção e consolidação de definições que adentram não apenas publicações científicas, mas também textos de cunho estatutário. Acalorados debates e direções multifacetadas na composição de argumentos vão se desenovelando. 
As diferentes definições de morte cerebral que surgiram a partir dos anos $197^{\circ-}$ whole-brain death, brainstem death e higher brain death - foram aqui resgatadas. Tevese por foco dar destaque às publicações e autores que sustentam, a partir de teses diferentes, descrições de ser humano conjugadas à definição de morte cerebral que propõem. O debate que se seguiu à proposta de redefinição da morte nos Estados Unidos tinha como principal finalidade tornar legal a nova definição, de maneira a circunscrever a morte nos limites da prática médica, mas com amplo reconhecimento público e jurídico da autoridade dessa ciência para delimitar o que é a morte, a vida e o ser humano. Essa foi a jornada da medicina por mais de uma década, entre o final dos anos 1960 e o início dos anos 1980, no que se refere à definição de morte cerebral. Alguns periódicos médicos se sobressaíram como veículo de divulgação das variantes da nova definição de morte e importantes coletivos de médicos, filósofos e juristas se formaram para fortalecer suas teses. Analisou-se esse contexto de produção de ideias que se seguiu à definição de morte cerebral em solo norte-americano.

As definições de whole-brain death, brainstem death e a higher brain death ganham destaque nesse processo histórico de construções de argumentos. Para alçar o status de "boa" definição, vão se apoiando em definições específicas de ser humano. Emergindo pela presença do "organismo", do "cérebro", da "pessoalidade", da "identidade pessoal" ou de "estabilidade moral", contornos do que é o ser humano vão sendo apresentados nesse processo de redefinição da morte que se desenrola entre 1960 e 1990, tendo alguns de seus argumentos reeditados em publicações mais recentes.

Sua versão "médico-forense", a whole-brain death, expande-se para outros países, dentre eles o Brasil, nas trocas internacionais de práticas e ideias que aconteciam de modo concomitante e posterior à definição de morte cerebral. Seu sucesso em pautar políticas públicas de doação de órgãos demonstra a versatilidade de uma definição a princípio rumorosa, mas com notável viabilidade para se sustentar diante dos avanços tecnológicos a ela agregados. A despeito dos questionáveis vieses morais que dela se desdobram, a definição de morte cerebral consegue estabilizar-se como fato médico. Mesmo as controvérsias suscitadas pela definição de morte cerebral que culminam nas derivações aqui discutidas contribuem para sua consolidação.

Observa-se, no processo mesmo de embates e redefinições, certa margem de negociação revelada na disseminação de uma afirmação. No caso da definição de morte cerebral, a possibilidade de que fosse interpretada e redesenhada em sua apropriação por diferentes campos de conhecimento, contextos institucionais e países, confere-lhe força e contribui para sua ampla proliferação. Vimos isso acontecer ao acompanhar as declarações de alguns dos principais atores engajados no debate da morte cerebral.@ 


\title{
INTERMITÊNGIAS DA MORTE...
}

Agradecimentos. O texto é inédito e aborda parte de pesquisa desenvolvida durante o doutorado, no Instituto de Medicina Social (IMS/UERJ), sob orientação do professor Francisco Ortega a quem agradeço pela boa parceria de trabalho. A pesquisa contou com financiamento da CAPES para período de estudos no Instituto Max Planck para a História da Ciência.

\section{Luciana Kind}

Professora Adjunto do Departamento de Psicologia, Programa de Pós-Graduação em Psicologia, Pontifícia Universidade Católica de Minas Gerais, Brasil. lukind@gmail.com

\begin{abstract}
This paper presents different definitions of brain death, as part of the process of sketching the construction of brain death as a medical fact. Since its publication at the end of the 1960 s in the Journal of the American MedicalAssociation, the definition of brain death has drawn both adherents and opponents. In order to be deployed in statutory texts, in the early 1980 s, the definition was reshaped and consolidated as whole-brain death. In the course of that process, other definitions had been offered as alternatives to the whole-brain death, such as brainstem death and higher brain death. Since each definition was supposed to provide a 'good' definition of death, it was linked with a specific conception of "human being". Different conceptions of human being were articulated with the redefinitions of death that were proposed between the 1960's and the 1990's. In some of these conceptions, location in the brain or in the organism as whole is fundamental; in others, the presence of "personhood", "personal identity" or "full moral standing".
\end{abstract}

KEYwords $\bullet$ Brain death. Conceptions of human being. Whole-brain death. Brainstem death. Higher brain death.

\section{REFERÊNGIAS BIBLIOGRÁFIGAS}

Ad Hoc Соммтттеe of the Harvard Medical School to Examine the Definition of Brain Death. Adefinition of irreversible coma. Journal of the American Medical Association, 205, 6, p. 337-4.0, 1968.

Andrieu, B. La neurophilosophie. Paris: PUF, 1998.

Arnold, J. D.; Zimmerman, T. F. \& Martin, D. C. Public attitudes and diagnosis of death. Journal of the American Medical Association, 206, 8, p. 1949-54, 1968.

BELKIN, G. S. Brain death and the historical understanding of bioethics. Journal of the History of Medicine, 58 , p. $325-61,2003$.

Bernat, J. L.; Culver, G. M. \& Gert, B. On the definition and criterion of death. Annals of Internal Medicine, 94, p. 389-94, 1981.

Bernat, J. L. How much of the brain must die in brain death? The Journal of Clinical Ethics, 3, 1, p. 21-6, 1992.

. The biophilosophical basis of whole-brain death. Social Philosophy and Policy, 19, p. 324,-42, 2002. 
Bernat, J. L. The concept and practice of brain death. Progress in Brain Research, 150, p. 369-79, 2005.

Bourdieu, P. As condições sociais da circulação internacional das ideias. Enfoques - Revista Eletrônica, l, 1, p. iv-xv, 2002.

Brody, B. How much of the brain must be dead? In: Youngner, S. J.; Arnold, R. M. \& Schapiro, R. (Ed.). The definition of death: contemporary controversies. Baltimore: The John Hopkins University Press, 1999. p. $71-82$.

Capron, A. M. \& Kass, L. R. A statutory definition of the standards for determining human death: an appraisal and a proposal. University of Pennsylvania Law Review, 121, p. 87-118, 1972.

Collins, V. J. Limits of medical responsibility in prolonging life: guides to decisions. Journal of the American Medical Association, 206, 2, p. 389-92, 1968.

Crowley-Mатока, M. \& Lock, M. Organ transplantation in a globalised world. Morality, 11, 2, p. 166-81, 2006.

DiBardino, D. J. The history and development of cardiac transplantation. Texas Heart Institute Journal, 26, 3, p. 198-205, 1999 .

Ehrenberg, A. Le sujet cérébral. Esprit, 309, p. 130-55, 2004.

FLECK, L. Genesis and development of a scientific fact. Chicago: The University of Chicago Press, 1979.

GraY, C. Twice dead: organ transplants and the reinvention of death. British Medical Journal, 324, p. 14,01, 2002.

Green, M. B. \& Wikler, D. Brain death and personal identity. Philosophyand Public Affairs, 9, 2, p. 105-33, 1980.

Jennett, B. \& Hessett, C. Brain death in Britain as reflected in renal donors. British Medical Journal, 283, p. $359-62,1981$.

Kind, L. Aproximações entre a psicologia social e a saúde coletiva. In: Mayorga, G. \& Prado, M. A. M. (Ed.). Psicologia social: articulando saberes e fazeres. Belo Horizonte: Autêntica, 2007. p. 255-69.

. Máquinas e argumentos: das tecnologias de suporte da vida à definição de morte cerebral. História, Ciência, Saúde-Manguinhos, 16, 1, p. 13-34, 2009.

Lamb, D. Diagnosing death. Philosophy and Public Affairs, 7, 2, p. 144--53, 1978.

Developments in brain death: challenges to the standard concept. New Review of Bioethics, 1, 1, p. 159-68, 2003.

Latour, B. Ciência em ação: como seguir cientistas e engenheiros sociedade afora. São Paulo: Unifesp, 2000. . Um coletivo de humanos e não-humanos: no labirinto de Dédalo. In:__ esperança de Pandora: ensaios sobre a realidade dos estudos científicos. São Paulo: EDUSC, 2001. p. 201-4,6.

LizzA, J. P. Persons, humanity, and the definition of death. Baltimore: The John Hopkins University Press, 2006.

Locke, J. Ensaio sobre o entendimento humano. Lisboa: Fundação Calouste Gulbenkian, 1999.

Mayorga, C. \& Prado, M. A. M. (Ed.). Psicologia social: articulando saberes e fazeres. Belo Horizonte: Autêntica, 2007.

OrTEGA, F. \& VidAL, F. Mapping the cerebral subject in contemporary culture. Revista Eletrônica de Comunicação Informação \& Inovação em Saúde, 1, 2, p. 255-9, 2007.

Pallis, C. Medicine and the media. British Medical Journal, 281, p. 1664, 1980. . ABC of brain stem death. Reappraising death. British Medical Journal, 285, p. 14,09-12, 13 Nov. $1982 a$. $\mathrm{ABC}$ of brain stem death. From brain death to brain stem death. British Medical Journal, 285 , p. $1487-90,20$ Nov. 1982 b.

. ABC of brain stem death. Diagnosis of brain stem death-I. British Medical Journal, 285, p. 1558-60, 27 Nov. $1982 \mathrm{c}$.

ABC of brain stem death. Diagnosis of brain stem death-II. British Medical Journal, 285, p. 1641-4, 4. Dez. 1982d. 


\section{INTERMITÊNGIAS DA MORTE...}

PALLIs, C. ABC of brain stem death. Pitfalls and safeguards. British Medical Journal, 285, p. 1720-2, 11 Dez. $1982 \mathrm{e}$.

. ABC of brain stem death. The declaration of death. British Medical Journal, 286, p. 39, I Jan. 1983a. . ABC of brain stem death. Prognostic significance of a dead brain stem. British Medical Journal, 286, p. 123-4, 8 Jan. 1983b.

ABC of brain stem death. The position in the USA and elswhere. British Medical Journal, 286, p. 209-10, 15 Jan. 1983c.

ABC of brain stem death. The arguments about EEG. British Medical Journal, 286, p. 284-, 22 Jan. 1983 d.

. ABC of brain stem death. London: British Medical Journal Publishers, 1983e.

On the brainstem criterion of death. In: Youngner, S. J.; Arnold, R. M. \& Schapiro, R. (Ed.). The definition of death: contemporary controversies. Baltimore: The John Hopkins University Press, 1999, p. 93-100.

Pallis, C. \& Harley, D. H. The ABC of brains death. 2. ed. London: British Medical Journal Publishing Group, 1996.

PaPA Pio XII. Reanimatione [The prolongation of life].Acta Apostolicae Sedis, p. 1027-33, 24 de novembro de 1957 .

Pernick, M. S. Brain death in a cultural context: the reconstruction of death, 1967-1981. In: Youngner, S. J.; Arnold, R. M. \& Schapiro, R. (Ed.). The definition of death: contemporary controversies. Baltimore: The John Hopkins University Press, 1999, p. 3-33.

President's Comission for the Study of Ethical Problems in Medicine and Biomedical and Behavioral Research. Journal of the American Medical Association, 24,6, 19, Nov. 1981a.

Defining death: medical, legal, and ethical issues in the determination of death. Washington: US Government Printing Office, 1981b.

Ramsey, P. The patient as person. New Haven: Yale University Press, 1970.

Richardson, R. Fearful symmetry: corpses for anatomy, organs for transplantation. In: Youngner, S. J.; Fox, R. C. \& O'Connel, L. J. (Ed.). Organ transplantation. Meanings and realities. Madison: The University of Wisconsin Press, 1996. p. 66-100.

Shewmon, A. The brain and somatic integration: insights into the standard biological rationale for equating "brain death" with death. Journal of Medicine and Philosophy, 26, 5, p. 457-78, 2001.

Stevens, T. Redefining death in America, 1968. Caduceu, 11, 3, p. 207-19, 1995.

VЕAтch, R. M. Death, dying and the biological revolution: our last quest for responsibility. New Haven: Yale University Press, 1976.

. Whole-brain, neocortical and higher brain related concepts. In: ZANer, R. M. (Ed.). Death beyond whole-brain criteria. Dordrecht: Kluwer Academic Publishers, 1988. p. 171-86.

. Death, dying and the biological revolution: our last quest for responsibility. ed. rev. New Haven: Yale University Press, 1989.

. The conscience clause: how much individual choice in defining death can our society tolerate? In: Youngner, S. J.; Arnold, R. M. \& Schapiro, R. (Ed.). The definition of death: contemporary controversies. Baltimore: The John Hopkins University Press, 1999. p. 137-60.

. The dead donor rule: true by definition. American Journal of Bioethics, 3, 1, p. 10-1, 2003.

The death of whole-brain death: the plague of the disaggregators, somaticists, and mentalists. Journal of Medicine and Philosophy, 3o, p. 353-78, 2005 .

VIDAL, F. Le sujet cerebral: une esquisse historique et conceptuelle. Psychiatrie, Sciences Humaines, Neurosciences, 3, 2, p. 37-4,8, 2005 .

Brainhood, anthropological figure of modernity. History of the Human Sciences, 22, 1, p. 5-36, 2009. 
Youngner, S. J.; Arnold, R. M. \& Schapiro, R. (Ed.). The definition of death: contemporary controversies.

Baltimore: The John Hopkins University Press, 1999.

Youngner, S. J.; Fox, R. C. \& O'ConneL, L. J. (Ed.). Organ transplantation. Meanings and realities. Madison: The University of Wisconsin Press, 1996.

ZANer, R. M. (Ed.). Death beyond whole-brain criteria. Dordrecht: Kluwer Academic Publishers, 1988. 